\title{
Dried blood spot sampling for quantitative bioanalysis: time for a revolution?
}

"Dried blood spot sampling ... will become an accepted part of the drug-development landscape of the future. The revolution is here!"

Well here we are again! Following hot on the heels of the special focus issue of Bioanalysis dedicated to dried blood spots in August 2010, we have another special issue concentrating on the same subject. The large volume of highquality contributions in these two editions and the numerous dedicated conference sessions and workshops on this subject in the last 2 years is rapidly contributing to a broader understanding and acceptance of this technique by the drug bioanalysis community. However, the work of this community is increasingly highly regulated, which naturally leads to a conservative approach and in-depth questioning of any new technologies. This is resulting in a number of members of the community holding back on implementing any real change, whilst they wait for others to trip up, or for the regulators to make a proclamation etched in stone about the suitability of the technique. Whilst this may at times be 'irritating' to the leaders who just want to get out there and do it - "isn't it obvious?" - this is an understandable reaction that must be heard. We need to take the time to thoroughly understand the technique and to perform the best science possible. However, it is my belief that we should not let all the understandable questions and reservations bury the pure fact that there are real benefits to be had with this technique. Standing still is not an option. The pressure from society to deliver ethical and environmentally friendly solutions is ever present. Added to this is the need of the pharmaceutical industry and healthcare providers to get better value for their money. Dried blood spot sampling delivers on all these aspects in spades and so will become an accepted part of the drug-development landscape of the future. The revolution is here!

Anyway, enough of my rant! I welcome you to this special focus issue of Bioanalysis dedicated to dried blood spot sampling. I would like to thank the authors for sharing with us their high-quality science and discussion. I would also like to thank the dedicated and hard work of the editorial staff for putting together this special issue.

Financial \& competing interests disclosure The author is an employee of GlaxoSmithKline (GSK) Research and Development and is eligible for GSK stock options and has stock ownership. The author has no other relevant affiliations or financial involvement with any organization or entity with a financial interest in or financial conflict with the subject matter or materials discussed in the manuscript apart from those disclosed.

No writing assistance was utilized in the production of this manuscript.

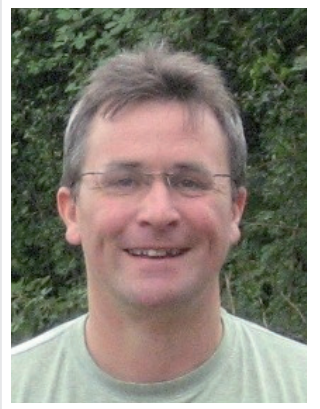

\section{Neil Spooner}

Platform Technologies \& Science Drug Metabolism \& Pharmacokinetics, GlaxoSmithKline Research \& Development, Ware, Hertfordshire, SGI2 ODP, UK

Tel.: +441920 882550

Fax: +44 1920884140

E-mail: neil.spooner@gsk.com 